HIV AND ASSISTED REPRODUCTIVE TECHNOLOGIES

\title{
Should HIV discordant couples have access to assisted reproductive technologies?
}

\section{Spriggs, T Charles}

J Med Ethics 2003;29:325-329

In this paper we identify and evaluate arguments for and against offering assisted reproductive technologies (ART), specifically IVF, to HIV discordant couples (male partner HIV positive, female partner HIV negative). The idea of offering ART to HIV discordant couples generates concerns about safety and public health and raises questions such as: what is an acceptable level of risk to offspring and should couples who want this assistance be subject to selection criteria; should they undergo scrutiny about their suitability as parents when those who are able to conceive naturally face no such scrutiny and people with other illnesses are given access to ART? We conclude that offering ART to HIV discordant couples is likely to produce more benefit than harm and violates no ethical principles. Nevertheless, a decision to deny treatment need not constitute unjustified discrimination.

See end of article for authors' affiliations

\section{Correspondence to:} M Spriggs, Ethics Unit, Murdoch Childrens Research Institute, Royal Childrens Hospital, Flemington Road, Parkville, Victoria 3052, Australia: spriggsm@murdoch.rch. unimelb.edu.au

Accepted for publication 17 December 2002
$\mathrm{P}$ eople infected with human immunodeficiency virus (HIV) are living longer and experiencing improved health. Substantial advancements in treatment mean that from the time of diagnosis, an adult infected with HIV who has access to treatment, can expect to live for "at least 20 years". ${ }^{2}$ The prospect of better health and increased life expectancy means that the idea of becoming a parent is not out of the question and some people with HIV want children. And they want access to assisted reproductive technologies (ART) which may reduce the risk of transmission to uninfected partners and offspring.

Heterosexual transmission of the virus is low, but a risk does exist. For HIV discordant couples where the male partner is positive and the woman is negative, a technique known as "sperm washing" is a way to further reduce the risk of transmission. The technique, pioneered by Augusto Semprini in Milan, involves the "washing" of semen to remove everything but the actual spermatozoa. ${ }^{3}$ After washing, the sperm can be combined with ova from the female partner using in vitro fertilisation (IVF) techniques or direct injection of the sperm into a selected oocyte-intracytoplasmic sperm injection (ICSI). Since the technique has been offered, three hundred children have been born with no reports of seroconversions in children or uninfected partners.

Sperm washing with IVF or ICSI is routinely offered by centres in Italy and Spain, along with some other places. ${ }^{14}$ It is not readily available in the United States. In 1990 in Virginia, a woman seroconverted after being inseminated with her husband's sperm. No pregnancy resulted and while it has not been proven that it was the insemination techniques that caused the infection, the US Center for Disease Control has been reluctant to support future trials until the procedure can be proved safe. ${ }^{156}$ In Melbourne, Australia, a hospital has recently decided to offer the procedure. In the past, Australian reproductive services have treated HIV discordant couples with artificial insemination using sperm from HIV negative male donors. But using donor sperm is not acceptable to some couples who want to have their own children. ${ }^{4}$ The Melbourne Hospital has now developed a protocol for the treatment of HIV discordant couples using their own gametes.

\section{THE ISSUES}

Safety and public health considerations figure prominently in the debate about offering ART to HIV discordant couples. The welfare of the child, prevention of harm, issues of discrimination, acceptable levels of risk, and the obligations of health care professionals also figure. Offering ART to HIV discordant couples raises questions such as: what is an acceptable level of risk to offspring and should couples who want this assistance be subject to selection criteria? Should they undergo scrutiny about their suitability as parents when those who are able to conceive naturally face no such scrutiny and people with other illnesses are given access to ART? It also raises the question of whether HIV differs in any morally significant way from other illnesses or conditions. Is it worse for a child to be born to a parent who is HIV positive than to a parent with some other condition?

In this paper we identify and evaluate the arguments for and against offering assisted reproductive technologies, specifically IVF, to HIV discordant couples. We also identify additional considerations of ethical relevance.

\section{ARGUMENTS AGAINST OFFERING ART TO HIV DISCORDANT COUPLES} Safety and public health considerations Safety and public health considerations form the basis of an argument against offering assisted reproductive technology to HIV discordant couples. The risk of transmitting the virus to an uninfected partner and to the resulting child is a major problem. This has led some people to the view that HIV positive people should not have children, because the magnitude of the risk, 
despite the low transmission rate, is too great to take. They think it is morally wrong to knowingly conceive a child under these circumstances. Even with improved prognosis and treatments, acquiring the disease is still a disaster.

Given that these objections exist, it is obvious that there will be objections to offering assisted reproductive technologies to someone who is HIV positive. Offering IVF to HIV discordant couples involves additional public health risks. There is a risk of infectious contamination of other embryos and a risk of virus transmission to clinical and laboratory staff and to other couples using the same facilities. ${ }^{8}$ The recent IVF mix up in which a white couple gave birth to black twins after the white woman's eggs were fertilised with a black man's sperm, is a reminder that mistakes can and do occur in IVF laboratories. ${ }^{9}{ }^{10}$ Mixing egg and sperm does not mean that the resulting child is going to be infected but mix ups are not desirable and clearly, donor gametes would not be accepted from someone infected with HIV.

The potential long term effects of zidovudine (AZT) and other antiretroviral agents create more safety issues. Zidovudine is highly effective in reducing the risk of vertical transmission of HIV from the mother to the fetus and also for reducing the viral load amongst adult patients. ${ }^{11-14}$ There are, however, inconsistent reports regarding its safety. ${ }^{15} 16$ Zidovudine is a nucleoside analogue drug that inhibits replication of HIV and during this process, incorporates itself into the host genome. Conflicting reports are available regarding the effects of treatment on sperm quality, motility, and number. ${ }^{17-19}$ In addition, there are documented cases of other health issues for adults on long term therapy and also for infants exposed to AZT from their mothers. ${ }^{15} 2021$ Another concern is whether having the drug incorporated into one's genetic material will have implications for offspring. Some people think that this kind of change to the genetic material could increase the risk of birth defects and cancer. There are also concerns that the change in germline cells may be passed down through generations.. ${ }^{422}{ }^{23}$ The disasters that arose from the use of thalidomide and diethylstilbestrol (DES) come to mind. Further research seems warranted and patients need to be informed of the uncertainty that exists about antiretroviral therapy and reproduction.

\section{Welfare of the child}

The welfare of the child provides the basis for another argument against giving HIV discordant couples access to ART. Even though the child may escape being infected, the child's welfare can be compromised. The reduced life expectancy of the infected parent will disadvantage the child. And some people think that "when the medical and the social realities are considered" a child born to someone with HIV is less likely to have a chance of a good life. ${ }^{124}$

Arguments about the welfare of the child cannot be disregarded in considering whether HIV discordant couples should have access to ART. The first guiding principle of Australia's Infertility Treatment Act (1995) is: "the welfare and interests of any person born or to be born as a result of a treatment procedure are paramount". ${ }^{25}$ The Human Fertilisation and Embryology Act 1990 states: "any fertility clinic in the UK offering treatment services, such as IVF ... must take account of the welfare of any child born as a result of the treatment ...". ${ }^{26}$

\section{ARGUMENTS FOR OFFERING ART TO HIV DISCORDANT COUPLES \\ Prevention of harm}

The argument that seems to carry the most weight for offering IVF to HIV discordant couples is that it prevents harm. In vitro fertilisation reduces the risk of the virus being transmitted to an uninfected partner and child. Denying treatment to couples will not stop transmission to uninfected partners and offspring because not offering the treatment does not mean the couple will give up the idea of having a child. If treatment is denied there is an increased risk of disease transmission from unprotected sex. ${ }^{1}$ What is more, if treatment is refused at one centre, the couple could seek treatment at another centre without disclosing their HIV status. This would put at risk staff and other patients who would not have the opportunity to decide whether it was a risk they were prepared to accept.

\section{It is unjustified discrimination to deny access to ART}

It can be argued that denying HIV discordant couples access to assisted reproductive technologies is unjustified discrimination because couples who can have children without reproductive assistance are not scrutinised in the same way. It is unjust to deny access to treatment on the basis of HIV status. To do so is to suppose that people with HIV are not suitable parents-and that their plan to have children demonstrates their unsuitability. Couples who conceive naturally do not have to justify their desire to have children. It is more common for couples to justify not having children. Furthermore, it is difficult to put into words what would be a good reason for having children. The "sorts of reasons that parents usually have (or do not have)" for wanting to have children seem "pathetically inadequate". ${ }^{27}$ Some of the reasons for having children are: to save a faltering marriage; a liking for children; to provide a brother or a sister for another child; pressure from older children to have another baby; to avoid having an "only child"; to replace a child who has died, and "completeness" in a family by having a child of each sex..$^{28}$ People often have children for no reason at all.

We have no reliable way of predicting who will or will not be a good parent and no agreed upon measure of what makes a good parent. It seems unreasonable to conclude that someone will not be a fit parent in advance of their being permitted to procreate. ${ }^{29}$ The difficulty and the impropriety of trying to assess fitness to parent was illustrated recently when an Australian politician raised the possibility of introducing compulsory parenting classes and linking parenting, child care, and family payments to parenting performance: "You need a licence to catch a fish, you need a licence to own a dog, you need a licence to drive a car. Well there's no licence to have a child ..." .30 The proposal provoked a hostile reaction and was abandoned just hours after it was announced. ${ }^{31}$ Apart from disadvantaging further those who are already disadvantaged, the proposal shows the difficulty in assessing parents: who would choose the view of parenting to be promoted? Who is qualified to assess performance and how would it be assessed? Would failure to attend classes constitute "bad" parenting?

There are more ways still in which denying HIV discordant couples access to assisted reproductive technologies could be deemed unjustified discrimination. The treatment is offered to other people with other terminal illnesses, such as those with heart disease and those with leukaemia. Also, we neither condemn, nor prevent from reproducing, those whose children may inherit a genetic illnesses or disability. Couples who are at risk of having a child with cystic fibrosis or Tay Sachs disease sometimes risk having an affected child rather than forgo parenthood. And if a test result is positive, some couples choose not to terminate a pregnancy even though the child they are having will be born with cystic fibrosis or Tay Sachs. ${ }^{5}$ In light of this, there seems to be no justification for denying HIV discordant couples assistance with reproduction. Unless HIV differs in a morally significant way from other illnesses, being HIV positive does not mean that having an ill child is a greater calamity than couples at risk of cystic fibrosis or Tay Sachs having an ill child. ${ }^{8}$ 


\section{ASSESSMENT OF ARGUMENTS AGAINST OFFERING ART TO HIV DISCORDANT COUPLES \\ Safety issues}

Can we justify denying HIV discordant couples access to ART on the grounds that there may be a risk to the child? Parents without HIV can, usually without public scrutiny, engage in activities that pose some risk to their child. Maternal age is a risk factor for birth defects ${ }^{32}$ but there is no call to limit childbearing to women under 37 . And, as a society, we seem to tolerate risk to offspring. Many women need to take medication during pregnancy but there has been no public outcry about the fact that more than 90 per cent of new prescription drugs coming on to the market are not properly tested to ensure they do not cause birth defects in pregnant women. Pregnant women have been excluded from drug studies because of the risk to the fetus and when the drugs come on to the market and are prescribed to pregnant women they are generally not tested for safety or efficacy in pregnant women. This puts at risk women such as those with epilepsy who need to continue medication when pregnant. ${ }^{33}{ }^{34}$

A study published in the New England Journal of Medicine reports that children conceived with the use of assisted reproductive technology have a greater chance of being born with a major birth defect than children conceived in the usual way-they are more likely to have "multiple major defects and to have chromosomal and musculoskeletal defects". ${ }^{35}$ If we are serious about avoiding risk we should deny access to everyone-but this has not happened and is not likely to happen. It seems that rather than actual risk, it is the fear and stigma of HIV that influences people's attitudes.

There is a kind of distortion in the way "risk" is framed in conjunction with HIV that serves to identify villains and victims and to cast blame. This is illustrated in the analysis of the news media coverage of HIV/AIDS risk and a Sydney doctor who was HIV positive and operated on 149 obstetric patients. The women he operated on were at "infinitesimal risk" and none of them actually acquired HIV but the reporting magnified the alarm and the level of risk. People such as gay men and injecting drug users, who are identified as being at "high risk" of HIV infection are typically depicted as "deviant, worthy of blame and stigmatisation for 'allowing' their bodies to become infected". ${ }^{36}$

Safety is not the issue if reactions to the question of reproductive assistance for HIV discordant couples change when we are referring to HIV infected haemophiliac men and their partners. It would seem that unacknowledged judgments about how the disease was acquired are at work. Nevertheless, issues of stigma aside, we can still ask if HIV differs in any morally significant way from other illnesses or conditions.

\section{Welfare of the child}

In terms of the welfare of the child, someone could argue that there may be morally significant differences in how the parent's disease was acquired. It may be worse for a child to be born to a parent who acquired the disease through injecting drugs than to be the child of a haemophiliac who contracted the disease through infected blood.

\section{ASSESSMENT OF ARGUMENTS FOR OFFERING ART TO HIV DISCORDANT COUPLES \\ Prevention of harm}

Arguments about IVF reducing the risk of the virus to uninfected partners and offspring raise the question of whether a couple's desire for genetically related children justifies any level of risk of HIV transmission. Using donor sperm could eliminate this risk altogether. The risk of virus transmission comes about because HIV discordant couples want their own genetically related children. ${ }^{45}$ This raises the further question of whether there is something about genetic relatedness that justifies the risks and any costs of offering IVF to HIV discordant couples.

Giving HIV discordant couples access to IVF may be a risk reduction strategy in one way but it cannot be compared to reproductive assistance for people with other terminal illnesses or genetic conditions. Providing assisted reproductive technologies for HIV discordant couples is a different matter because it involves more than risk to offspring. It involves a risk to the mother as well and there is also risk for health care workers and other patients.

\section{It is unjustified discrimination to deny access to ART} Deciding not to treat an HIV discordant couple need not constitute unjustified discrimination. Assisted reproductive technologies are not universally available and those who want access generally have to undergo screening or counselling. A survey of America's 324 ART clinics found that more than half the services surveyed do not have written policies and that clinics often limit access. Many clinics screen for, and do not treat, patients who use alcohol excessively, have a history of child abuse or mental illness, or who are likely to transmit genetic diseases. The decision not to treat was found to be "most consistent" in cases where there were "clearly identified risks" and the example cited was treatment of HIV positive women "with definable risks of transmission to the offspring". ${ }^{38}$

The Melbourne treatment protocol for HIV discordant couples has a guideline for counselling by reproductive service counsellors. It lists "strength of marital relationship" as one of the topics to be addressed. We could quite reasonably think that counselling of this sort is an unnecessary intrusion, given that risk reduction and harm minimisation for HIV discordant couples is the stated aim. ${ }^{7}$

The fact that HIV discordant couples, like other patients wanting ART, are screened and may be denied treatment does not amount to unjustified discrimination. The difficulty is that unjust discrimination would not be easy to recognise because there is a lack of formal policy on access to service issues. ${ }^{38}$

\section{OTHER CONSIDERATIONS OF ETHICAL RELEVANCE Should HIV discordant couples wanting access to IVF techniques be subject to some kind of selection criteria?}

Consider the following case, which featured in a Minnesota radio report. A single, heterosexual, HIV positive male, a doctor who acquired the virus via a medical procedure, presents to a fertility clinic asking for assistance. He says he is willing to pay a surrogate mother to carry his child. He has been unable to find a woman who will marry him due to his HIV status and he is seeking support in finding a suitable surrogate and also with the IVF procedures to create the pregnancy. ${ }^{39}$

This situation is more problematic and raises a multitude of questions because of the involvement of a surrogacy arrangement. The potential for harm and exploitation suggests there are grounds for some kind of selection criteria.

\section{The obligations of health care professionals}

The following are some of the many questions that the obligations of health care professionals and ARTs raise: do health care professionals have an obligation to offer ART to HIV discordant couples? If a health care professional denies access and the uninfected partner or the child becomes infected through unprotected sex, who is responsible for the harm that has occurred? Is ART a medically legitimate treatment-in other words, is ART for HIV discordant couples a form of risk reduction or is it simply catering to self 
indulgent whims? Can ART be justified on grounds other than medical grounds? If it can be justified on non-medical grounds, do health care professionals still have an obligation to offer ART?

\section{Cost}

Is cost a factor in offering IVF to HIV discordant couples? On the grounds of risk reduction and harm minimisation, cost should not restrict access. It seems reasonable, however, if we consider resource priorities, to ask whether cost could be a constraint given that the risk of virus transmission existsand given that this risk could be eliminated except that HIV discordant couples want their own genetically related children.

The risks in offering HIV discordant couples IVF can be minimised by employing highly trained and experienced staff and by using separate laboratory areas and storage for high risk samples. ${ }^{2}{ }^{8}$ According to Wilde, the sperm washing technique is "extremely expensive". It is "very expensive to establish and run a sperm washing service" and cost "may be prohibitive for many couples in the UK". ${ }^{4}$ Should "high risk" patients be required to pay more for treatment than the regular candidate to cover these "extra" requirements?

Cost does not seem to be a problem for the authors of the Melbourne protocol. Apart from the "universal employment of standard precautions" which are relied on to "regularly treat Hep B and C positive patients by ART" there is no mention of a need for extra requirements or cost in relation to HIV discordant couples. ${ }^{7}$ Nevertheless, an implication of the use of IVF by HIV discordant couples is that the use of a service that is subsidised with public money justifies public scrutiny.

\section{CONCLUSION}

HIV discordant couples should be given access to "sperm washing" and IVF. Offering ART to HIV discordant couples violates no ethical principles and, on the whole, it seems likely to produce more benefit than harm, whereas in most cases a decision not to treat is likely to cause harm. At first glance, we might think that consistency suggests it would be unfair and discriminatory to deny HIV discordant couples access to IVF and that unacknowledged judgments are being made. The stigma of HIV does seem to figure in judgments in an illegitimate way but, as we have seen, there seem to be morally relevant differences in offering ART to HIV discordant couples. While these differences do not amount to an argument for denying access to HIV discordant couples in general, they are sufficient to justify scrutiny of HIV discordant couples wanting access to ART. If there is a significant risk to the child or to others in a particular casefor example, the HIV positive doctor seeking a surrogate and IVF to create a pregnancy, access can be denied.

\section{ACKNOWLEDGEMENTS}

This paper was presented at a MCRI/Monash University/University of Melbourne Bioethics Journal Club and has benefited from the discussion that followed.

\section{Authors' affiliations}

M Spriggs, Ethics Unit, Murdoch Childrens Research Institute, Royal Childrens Hospital/University of Melbourne. Centre for Human Bioethics, Monash University

T Charles, Mitochondrial Laboratory, Murdoch Children's Research Institute, Royal Childrens Hospital, Flemington Road, Parkville, Victoria, 3052, Australia

\section{REFERENCES}

1 Gilling-Smith C, Smith RJ, Semprini AE. [editorial], HIV and infertility: time to treat. BMJ 2001;322:566-7.
2 Englert Y, Van Vooren JP, Place I, et al. ART in HIV infected couples. Hum Reprod 2001;6:1309-15.

3 Semprini AE, Levi-Setti P, Bozzo M, et al. Insemination of HIV negative women with processed semen of HIV positive partners. Lancet 1992;340:1317-19.

4 Wilde J. Conception in HIV discordant couples. World Federation of Hemophilia. Treatment of Hemophilia Monograph Series. http:// www.wfh.org/Content_Documents/TOH_Monographs/TOH26_HIVdiscordant_couples.pdf and follow links for the index (accessed 3 Sept 2003).

5 ASRM (American Society for Reproductive Medicine) Ethics Committee. Human immunodeficiency virus and infertility treatment. Fertil Steril 2002;77:218-22

6 Anonymous. HIV 1 infection and artificial insemination with processed semen. MMWR Morb Mortal Wkly Rep 1990;39:249-56.

7 Baker HWG, Mijch A, Garland S, et al. Use of ART to reduce the risk of transmission in HIV discordant couples wishing to have their own children: male seropositive with undetectable viral load. J Med Ethics 2003;29:315-20.

8 Drapkin Lyerly A, Anderson J. Human immunodeficiency virus and assisted reproduction: reconsidering evidence, reframing ethics. Fertil Steril 2001;75:843-58.

9 Morris S. Clinics urged to tighten checks after embryo mix up. The Guardian 2002 Jul 10. http://www.guardian.co.uk/medicine/story/ $0,11381,751983,00 . \mathrm{html}$ (accessed $15 \mathrm{Jul}$ 2002).

10 Dyer C. Black father identified in IVF mix up. The Guardian 2002 Aug 1. http://www.guardian.co.uk/race/story/0,1 1374,767242,00.html (accessed 5 Aug 2002).

11 Hogg RS, O'Shaughnessy MV, Gataric N, et al. Decline in deaths from AIDS due to new antiretrovirals [letter]. Lancet 1997;349:1294.

12 Palella FJ, Delaney KM, Moorman AC, et al. Declining morbidity and mortality among patients with advanced human immunodeficiency virus infection. N Engl J Med 1998:338:853-60.

13 Sperling RS, Shapiro DE, Coombs RW, et al. Maternal viral load, zidovudine treatment, and the risk of transmission of human immunodeficiency virus type 1 from mother to infant. N Engl J Med 1996;335:1621-9.

14 Centers for Disease Control and Prevention. US Public Health Service task force recommendations for the use of antiretroviral drugs in pregnant women infected with HIV 1 for maternal health and for reducing perinatal HIV 1 transmission in the United States. MMWR Morb Mortal Wkly Rep 1998:47:1-30.

15 Blanche S, Tardieu M, Rustin P, et al. Persistent mitochondrial dysfunction and perinatal exposure to antiretroviral nucleoside analogues. Lancet 1999;354:1084-9.

16 Olaitan A, Reid W, Mocroft A, et al. Infertility among human immunodeficiency virus positive women: incidence and treatment dilemmas. Hum Reprod 1996; 11:2793-6.

17 Politch JA, Mayer KH, Abbott AF, et al. The effects of disease progression and zidovudine therapy on semen quality in human immunodeficiency virus type 1 seroposititve men. Fertil Steril 1994:61:922-8.

18 Crittenden JA, Handelsman DJ, Stewart GJ. Semen analysis in human immunodeficiency virus infection. Fertil Steril 1992;57:1294-9.

19 Muller CH, Coombs RW, Krieger JN. Effects of clinical stage and immunological status on semen analysis results in human immunodeficiency virus type 1 seropositive men. Andrologia 1998;30:15-22.

20 Haas RH. A comparison of genetic mitochondrial disease and nucleoside analogue toxicity. Ann NY Acad Sci 2000;918:247-61.

21 Brinkman K, ter Hofstede HJ, Burger DM, et al. Adverse effects of reverse transcriptase inhibitors: mitochondrial toxicity as common pathway. AIDS 1998; 12:1735-44

22 Marchione M. Does having a fatal disease rule out parenthood? Milwaukee Journal Sentinel 2002 Mar 11. www.jsonline.com/alive/column/marO2/ 26389.asp (accessed 5 Aug 2002).

23 Olivero OA, Fernandez JJ, Antiochos BB, et al. Transplacental genotoxicity of combined antiretroviral nucleoside analogue therapy in erythrocebus patas monkeys. J Acquir Immune Defic Syndr 2002;29:323-9.

24 Steinbock B, McClamrock R. When is birth unfair to the child? Hastings Cent Rep 1994;24:15-21.

25 Infertility Treatment Act 1995. Act no 63/1995. Version No 016. http:// www.dms.dpc.vic.gov.au/ (accessed 3 Sept 2003).

26 Human Fertilisation and Embryology Act 1990. (c 37). http:// www.hmso.gov.uk/acts/acts1990/Ukpga_19900037_en_1.htm laccessed 24 Sept 2002)

27 Harris J. The value of life. London: Routledge, 1985:154

28 Pohlman E. The psychology of birth planning. Cambridge: Schenkman Publishing Company, Inc, 1969:48-81.

29 Harris J. Rights and reproductive choice. In: Harris J, Holm S, eds. The future of human reproduction: ethics, choice, and regulation. Oxford: Clarendon Press, 1998:5-37.

30 Gray D. Enforced baby classes ruled out. The Age 2002 Aug 27;news:4.

31 Wallace R. Backdown on parent class plan. Herald Sun 2002 Aug 27;news:4.

32 State Government, Victoria, Australia. Disability on line: information for people with a disability, their families, and carers. Birth defects involving chromosomes - trisomy disorders. http://www.disability.vic.gov.au/ dsonline/dsarticles.nsf/pages/Birth_defects_involving_chromosomes (accessed 5 Aug 2002).

33 Lo W, Friedman J. Teratogenicity of recently introduced medications in human pregnancy. Obstet Gynecol 2002;100:465-73.

34 Spriggs M. Ethical implications of women's under representation in clinical trials. Monash Bioeth Rev 1999; 18(suppl): 1 1-20S.

35 Hansen M, Kurinczuk J, Bower C, et al. The risk of major birth defects after intracytoplasmic sperm injection and in vitro fertilisation. N Engl J Med 2002;346:725-30. 
36 Brown J, Chapman S, Lupton D. Infinitesimal risk as public health crisis: news media coverage of a doctor patient HIV contact tracing investigation. Soc Sci Med 1996;43:1685-95.

37 Fuscaldo G. Fatherless families: how important is genetic relatedness? Monash Bioeth Rev 2002;21:18-29.
38 Stern J Cramer C, Garrod A, et al. Access to services at assisted reproductive technology clinics: a survey of policies and practices. Am J Obstet Gynecol 2001; 184:591-7.

39 Smith S. The fertility race: HIV and fertility. http://americanradioworks.org/ features/fertility_race/ (accessed 5 Aug 2002).

\section{$\mathrm{ECHO}$}

\section{Hindsight and judgment}

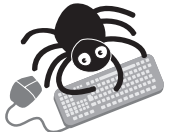

Please visit the Journal of Medical Ethics website [www. jmedethics. com] for a link to the full text of this article.
$T$

he American screenwriter and film director Billy Wilder referred to the perfect vision of hindsight; "hindsight is always twenty-twenty". But hindsight may also distort and prejudice our judgment of past events in a way that it is difficult to compensate for. A 28 year old paper, part of a doctoral dissertation submitted to the Hebrew University of Jerusalem, has been reprinted in Quality and Safety in Health Care under the heading "Classic Paper".

The three experiments described in this paper, together with a fourth referred to briefly, show that thinking that we know the outcome of a series of events, even if what we believe about the outcome is false, tends to make us consider that that series of events almost inevitably led to that outcome and that we and others should have had the foresight to have predicted it. This tendency has been called "creeping determinism".

In experiment 1 , subjects (non-medical university students) were each asked to read one of four 150 word passages. Two of the passages each described a different series of historical events and two were clinical case descriptions. For each series of events four possible outcomes were provided, one of them the actual outcome. Subjects were divided into five groups in each case; one group given no information about actual outcome, one told the true outcome, and the other three groups each told that a different one of the three false outcomes was the actual outcome. They were asked to assign a probability for each outcome in the light of information given in the passage, the four probabilities to add up to $100 \%$. In each case subjects given an outcome assigned a greater probability to that outcome than did subjects given no information about outcome. They also tended to assess the relevance of each piece of information provided in their passage according to the outcome they had been given. Thus the concept of creeping determinism was supported.

In experiment 2, subjects were asked to try to ignore what they had been told about outcome in assessing outcome probabilities. Again they tended to give a higher probability to the outcome they had been given and assessed the relevance of items of information accordingly. In experiment 3, subjects were asked to respond as they thought other students given no outcome data might respond. They again were biased towards the outcome they had been given. In the fourth experiment subjects were asked to predict the outcomes of a forthcoming event. They were later, after the event, asked to restate their predictions. Their memories were biased towards what they believed had proved to be correct predictions.

Interpretation of past events may be biased by belief (true or false) about the outcome of those events. This may lead to unjust criticism of self or others for reacting inappropriately to events that, in hindsight, appear to have led to an inevitable conclusion. It may also cloud judgments of history in general.

A Quality and Safety in Health Care 2003;12:304-12. 